\title{
ТЕОРЕТИЧЕСКИЕ АСПЕКТЫ И РАЗВИТИЕ МЕТОДОВ УПРАВЛЕНИЯ ИННОВАЦИЯМИ
}

\author{
(C) 2020 Рыбин Михаил Владимирович \\ доктор технических наук, заведующий кафедрой «Управления инновациями» \\ Международный институт энергетической политики и управления инновациями МГИМО \\ МИД России, Россия, Москва \\ E-mail:m.rybin@odin.mgimo.ru
}

(c) 2020 Воинов Александр Игоревич

кандидат экономических наук, доцент кафедры «Управления инновациями и коммерциализации интеллектуальной собственности»

Российская государственная академия интеллектуальной собственности, Россия, Москва

E-mail:vo_innov@mail.ru

Развитие теории инноваций, начавшееся в первой половине прошлого столетия, обрело как многочисленных апологетов, так и антагонистов. Однако процесс эволюции инновационных воззрений политэкономистов актуализируется. Усилия российских промышленных предприятий, заинтересованных в выводе на рынок новых продуктов, прежде всего должны направляться на обеспечение коммерциализации технологий, стратегически повышающих конкурентоспособность национальной экономики.

Ключевые слова: инновации, К-волны, НБИКС-конвергенции, коммерциализация технологий

\section{Введение}

Отличительной чертой текущего состояния мировой экономики является исключительно важная роль инноваций. Инновации апостериори представляют собой создание нового знания либо ранее неизвестной комбинации уже существующих знаний, воплощенное в новых продуктах или технологических цепочках и влияющее на цикличность экономического развития в глобальном контексте. Современные нововведения, в отличие, скажем, от новшеств начала $\mathrm{XX}$ века, имеют гораздо более радикальный характер. Процесс их распространения происходит не в пример быстрее и затрагивает значительно большее число секторов мировой экономики, повышая тем самым их наукоемкость.

В англоязычной литературе по тематике управления существуют устоявшиеся выражения, подчеркивающие прорывной, критически важный характер тех нововведений, которые обозначаются термином «инновация». Согласно международному документу «Руководство Осло» (Oslo Manuel), любая инновационная активность характеризуется прохождением ряда стадий, включая проведение научных исследований и разработок, приобретение передовых технологий и оборудования и т.д.

\section{Теоретические аспекты}

Инновационное промышленное производство обнаруживает сущность экономического содержания технологии как объекта товарноденежных отношений: стоимость, отделимость от ее разработчиков, возможность передачи, коммерциализации и капитализации. Характерная периодизация для $K$-волн (Кондратьевских волн) - 50 лет с допустимым отклонением в 10 лет (от 40 до 60 лет). Такие циклы соответственно состоят из чередующихся между собой фаз относительно высоких и относительно низких темпов экономического роста. Н.Д. Кондратьев выделял четыре эмпирические закономерности в развитии больших циклов: перед началом повышательной волны каждого большого цикла, а иногда и в самом ее начале наблюдаются значительные изменения в условиях хозяйственной жизни социума; периоды повышательных волн больших циклов, преимущественно, насыщены крупными социальными потрясениями и переворотами в жизни общества (войны, революции), чем периоды понижательных волн; понижательные волны больших циклов хозяйственной деятельности сопровождаются затяжной депрессией аграрного сектора; большие циклы экономической конъюнктуры определя- 
ются в том же едином процессе общей динамики экономического развития, где выявляются и средние циклы с их фазами подъема, кризиса и депрессии.

Данные закономерности «описываются так называемыми инфратраекториями, показывающими:

- какая часть потенциальной “рыночной ниши” для определенной макротехнологии уже освоена;

- какая часть пути в развитии рассматриваемой отрасли уже пройдена;

- в какой фазе естественного цикла она находится.» [1, с.36]

Понимание этого крайне важно, так как экономическая, научно-технологическая, образовательная, инновационная политика в различных странах напрямую зависят от фазы развития рассматриваемых отраслей. Введенное в научный оборот политэкономистами понятие технологического уклада является одним из основополагающих в методологии управления инновациями и безусловно сопряжено с К-волнами [2]. Теория определяет пять исторических укладов и два перспективных - VI и VII, где выделяют фундаментальное научное знание, лежащее в генезисе базовых технологий.

Другое ключевое понятие «инновация» было введено в научный оборот австрийским ученымэкономистом Йозефом Шумпетером в 1930-х гг. как измерение, применяемое при внедрении и использовании новых видов потребительских товаров, производственных и транспортных средств, рынков и организационных форм в промышленности. Согласно его воззрениям, $u_{\text {н- }}$ новации - сложная и дифференцированная деятельность с множеством взаимодействующих компонентов, находящихся в середине производственного процесса. Однако в последние десятилетия данное утверждение представляется не бесспорным. Всё заметнее становится тенденция смещения инновационного мышления и самих инноваций к стадии исследований и разработок, к применению моделей технологического прогнозирования для задания мировых трендов развития техносферы и обеспечения тотального стратегического доминирования в приоритетных отраслях.

Теоретическое содержание инноваций, как непосредственное осуществление новых комбинаций, отражающихся на всей динамике развития экономики, Й.Шумпетер определил в виде пяти типичных случаев. Задумывающих и осуществляющих инновации индивидов, ученыйэкономист называл предпринимателями. Реализуя инновационные решения, предприниматели имплементируют новые, прежде неизвестные, комбинации факторов производства. Это давало ему основание полагать, что предпринимательство (или предпринимательская способность) является четвертым фактором производства, не описанным ранее классиками экономической науки. Шумпетер считал волны инновационного развития дискретными во времени, называя «кластерами» (пучками) те отрезки времени, в которые происходит всплеск инноваций. В рецензии на его книгу «Циклы деловой активности» («Business Cycles») Саймон Кузнец также признавал дискретность научно-технических революций.

Идеи Й.Шумпетера о роли предпринимательства в инновационном процессе и дискретности инноваций во времени получили дальнейшее развитие в трудах многих современных зарубежных и отечественных исследователей. В частности, определение, данное известным американским специалистом по менеджменту Петером Друкером, отмечает: «Нововведение - это особый инструмент предпринимателей, средство, с помощью которого они используют изменение как шанс для разного рода бизнеса или услуг». Западногерманский исследователь инноваций Герхард Менш классифицировал их по трем группам: базисные, улучшающие и псевдоинновации. В 1975 г. ученый ввел в научный оборот понятие «технический способ производства», интерпретируя К-волны как жизненный цикл технического способа производства, представленный им в виде логистической кривой. Сегодня эти идеи частично вышли за границы экономической теории и стали практическими инструментами высокотехнологичных отраслей, где сам инновационный процесс в развернутом виде можно представить следующими фазами: фундаментальные исследования; прикладные исследования; прогнозирование спроса; разработка и проектирование; производство, позиционирование, сбыт.

Интенсификация научно-технического прогресса и становление индустрии 4.0 продолжили эволюцию классической политэкономической мысли. Генерирование инноваций происходит 8 естественном цикле развития макротехнологии, состоящем «из трех этапов: 
- становление фундаментальной и экспериментальной науки, идей, которые могут получить практическое воплощение, подготовка кадров, организация опытно-конструкторских разработок;

- создание непосредственно технологий, быстрое совершенствование выпускаемых продуктов, производство и начало реализации открывающихся возможностей;

- диффузия появившихся инноваций в существующую техносферу и экономическую систему.» [1 с.35; 3]

Вместе с тем распространение конвергирующей междисциплинарной парадигмы NanoBioInfoCognito (НБИК-технологий) актуализирует проблематику пролонгирования глобального инновационного императива, сохранения не только окружающей среды, но и человеческой цивилизации. В свою очередь, Френсис Фукуяма склонен к рассмотрению ее как проблемы постчеловеческого будущего. Необходимо отметить, что в современных исследованиях прослеживается тенденция слияния социальных технологий с НБИК-технологиями, обозначаемых аббревиатурой НБИКС [4]. В этой связи НБИКС-конвергенции обсуждаются как базис социального прогресса, представляя собой концепцию управления развитием техносферы, проект совершенствования возможностей человека на основе методологии саморазвития и сложности. В холистической парадигме [5] индивид способен встраиваться в эволюционный процесс, отчего сам процесс обретает новую сложность. Так, одна из задач многолетнего поиска Института в Санта-Фе заключается в превращении открытия сложности в метод познания сложности.

До недавнего времени естественному циклу развития макротехнологии экономическая теория отводила 30-45 лет. С другой стороны, теорема Фурье показывает вероятность любой функции на некотором отрезке быть разложенной в сумму периодических (циклических) функций. В таком случае, если рассматривать мировую экономику за последние 250 лет, то не вполне исключено, что среди этих циклов присутствуют и 20-30 летние. Скепсис ряда исследователей обусловлен тем, что при выборе, скажем, несколько другого отрезка циклы могут получиться иными.

В этой связи сторонникам теории цикличности волн инноваций дать достаточно убедительное социологическое, и даже экономическое, объяснение тому, как в исторически-временном контексте происходит развитие технологий, которое ведет к старту очередного цикла, позволяет теория техноценоза. В последнее десятилетие, акцентируясь на сфере прорывных технологий, нельзя не учитывать эту теорию американских ученых Л.Г.Бадалян и В.Ф.Криворотова, отвечающую на весьма актуальный сегодня вопрос - какой период из прошлого наиболее близок к ситуации нынешнего экономического спада при продолжающейся глобализации, слабеющими центрами силы и быстро растущими бывшими странами-аутсайдерами. В соответствии с данной теорией, не фальсифицируемой общими словами, а лежащей в качестве одной из методологических основ научной деятельности Института сложности в Санта-Фе, «осмысление прошлого, стратегический прогноз требуют комплексного, системного анализа техноценозов, включающих в себя:

- осваиваемую и используемую территорию;

- главный энергоноситель;

- применяемые экономические технологии и управленческие системы;

- характеристики “человеческого капитала”, ключевые с точки зрения выживания и развития в определенных природно-климатических условиях.» [6]

В таком измерении сформированная государством национальная инновационная система (НИС) обеспечивает целостность инновационного процесса посредством углубления фундаментальных знаний, генерирования концептуальных идей, прикладных и экспериментальных НИР, коммерциализации интеллектуальной собственности, трансфера высоких технологий, инвестирования в сферу НИОКР и модернизацию промышленного производства, диффузии нововведений. При оценке ключевых показателей эффективности НИС, как фундаментальные цели ее функционирования, выделяют два индикатора: рост объема инновационно-насыщенных товаров на рынке; увеличение доли инновационной продукции в ВВП страны. В то же время только показатель доли действующего техноуклада в экономике государства определяет его роль и место в системе мирохозяйственных связей.

\section{Развитие методов}

Адсорбция технологических нововведений в мировом масштабе, формирующая ядро технологического уклада [7; 8], невозможна без уча- 
стия международных сообществ инноваторов. Так, Программа (стратегия) развития наноиндустрии Китая в 2005 г. отводила национальному рынку нанопродуктов \$5,4 млрд., а к 2015 г. планировалось его увеличение до \$144,8 млрд. В период 2015-2018 гг. только продажи смартфонов на территории страны достигли 1,725 млрд. штук, до 2/3 которых пришлось на долю китайских производителей нанотеха, входящих в 2020 г., согласно статистике Американского бюро по регистрации патентов и торговых марок (USPTO), в четверку мировых стран-флагманов по количеству нанотехнологических патентов. Глобальная сетевая структура, сложившаяся, в том числе, и вокруг Института сложности, главной целью деятельности которой стало участие в проектировании будущего человеческой цивилизации, анализе прямых и косвенных воздействий, способных через годы и десятилетия изменить ситуацию в конструируемом направлении. Как следствие новые технологии могут появляться на вершине цикла, но не вписываться в уже заданные мировым инновационным сообществам восходящие технологические тренды. Накопленные прорывные разработки начинают «выстреливать» на его дне тогда, когда эти тренды оказываются нисходящими. Например, особое место в имплементировании новой отраслевой стратегии Великобритании занимает деятельность «катапультных», или «запускающих» национальных инновационных центров (Catapults Centres) [9], нацеленных на ускорение коммерциализации технологий VI уклада.

Отдельного упоминания заслуживает и такой метод коммерциализации как «венчурные бумы». «В среднем, общемировой венчурный цикл занимает около десятилетия. В прошлом рынок рискового капитала испытывал несколько периодов подъема: 1964-1971 гг., 1978-1987 гг. и 1994-2000 гг. Низшие точки спада пришлись, соответственно, на 1975, 1992 и 2003 года. Конечно, первыми движение волны видят лишь инсайдеры. Когда подъем заметят все, весьма вероятно, что бум уже давно на пике и пора готовиться к спаду.

Оживление американской экономики, продолжавшееся с 2004 по 2007 гг., а также после 2010 г. сказалось и на публичном рынке. Тайваньская компания «Semiconductor Manufacturing International Corp.» (SMIC) в 2000 г. провела IPO на сумму \$1,8 млрд., что на тот момент стало историческим максимумом. Предыдущим ре- кордом была телекоммуникационная компания «Corvis», которая ранее в 2000 г., почти на самой вершине рынка, проводила IPO, чуть превысившее \$1 млрд. Но эти максимумы продолжили свое обновление - «Google» (\$23 млрд. (2004 г.)), «Twitter» (\$24 млрд. (2013 г.)), «Alibaba» (\$238 млрд. (2014 г.)).» [10]

Ядром первого венчурного бума 1960-х гг. была микроэлектроника, бума 1970-1980-х гг.персональные компьютеры, 1990-х - Интернет и цифровые технологии [11], середины 2000-х интернет-ресурсы и онлайн-приложения. Сегменты венчурного бума, начавшегося с 2012 г. и вышедшего на свои пики роста в 2018 г., включают онлайн-сервисы, электронную коммерцию и финтех. Например, в КНР суммарная стоимость компаний, продвигающих платежные интернетплатформы, по итогам 2018 г. превысила 1,6 трлн. юаней. «Что же станет основой для следующего мирового инновационного рывка? Если делать прогнозы, то драйверами ближайшего десятилетия, бесспорно, являются метаматериалы и нанобиоэлектроника, сингулярность, генная терапия, фабрики будущего, “зеленое” и беспилотное автомобилестроение. Итак, 20162022 гг. способны оказаться благоприятнейшим периодом для агрессивных технологических инвестиций в прорывные компании, и, по многим признакам, самые опытные венчурные капиталисты уже выбрали стартапы, вписывающиеся в техноэкономическую парадигму VI уклада.» [10].

Обзоры консалтинговых фирм «McKinsey» и «Sand Hill Group» показывают, что первое место в рейтинге офшорных разработок для корпораций из Соединенных Штатов с большим отрывом занимает Индия. До 3/4 американских компаний планируют здесь свои исследования как у аутсорсера инноваций. В списке лидеров Китай, Восточная Европа (включая Россию) и страны Североамериканской зоны свободной торговли.

Технологические аналитики ввели в профессиональный оборот термин «мастерские скунсов» (skunk works), которым в международном инновационном бизнесе обозначаются «группы прорыва», работающие в режиме удаленности и фриланса над концептуальными проектами с целью сделать нечто принципиально новое или решить пока неразрешимые задачи [12]. Иностранные мастерские транснациональных корпораций, специализируются на высокотехнологичных программных продуктах в начальных стадиях, где создается базовая технология, дово- 
димая до конечного продукта уже внутренними структурными подразделениями.

С другой стороны, факт включенности компаний сектора наукоемких отраслей в международные сети венчурной акселерации повышает шансы на успех и серьезно увеличивает их возможности по извлечению максимальной коммерческой выгоды из обширных сетевых сообществ инноваторов [13; 14].

Между тем важнейшим индикатором геоэкономической устойчивости государства является доля высокотехнологичных товаров (авиационно-космической техники, фармацевтики, научных приборов, компьютеров и наноэлектроники) в экспорте страны. По данным Всемирного банка за 2014 год, показатель Российской Федерации крайне низок - всего 2\%, хотя в 2000 г. (на фоне падения мировых цен на углеводороды) он составлял 4\%. Практический интерес представляет опыт Польши, которой за 15 постреформенных лет удалось увеличить долю высокотехнологичных товаров в своем экспорте с 3\% до 7\%.

В современных условиях новой экономической нормальности после существенного снижения в 2020 г. мировых нефтяных котировок инновации обретают особую роль, детерминирующую постепенную смену всей парадигмы социально-экономического развития России: от предыдущего промышленного этапа,- базировавшегося на расширении масштабов производства продуктов и добыче сырьевых ресурсов,- к экономике знаний [15; 16; 17].

Для адсорбции инноваций в национальном хозяйстве в равной степени необходимы три свойства НИОКР: научно-техническая новизна, производственная применимость, коммерческая реализуемость [18]. Помимо названных свойств НИОКР для отнесения оцениваемой технологии к инновационной в российских компаниях с госучастием учитывают текущий технический уровень разработок и не известные ранее потребительские свойства. Также следует выделить признаки, позволяющие отнести продукцию, изготовленную по оцениваемой технологии, к инновационно-насыщенной:

1. наличие улучшающих эксплуатационных, технических и других потребительских характеристик;

2. отнесение к новому виду или поколению техники, подтверждаемого результатами патентных исследований для НИОКР и требовани- ями ГОСТ Р 15.011.96;

3. способность к охране патентами или в качестве секрета производства, относящимися непосредственно к объекту разработки или к его составным частям;

4. допустимые сроки вывода на российский рынок продукции, изготовленной по оцениваемой технологии, не должны превышать 3-5 лет (ГОСТ 2.103-2013, ГОСТ Р 15.301-2016).

Признание оцениваемой технологии высокотехнологичной сопряжено с отнесением к наукоемким отраслям национальной экономики, в том числе в соответствии с Указом Президента РФ «Об утверждении приоритетных направлений развития науки, технологий и техники в Российской Федерации и перечня критических технологий Российской Федерации» [19]. Технологичность и последующая коммерциализуемость в ходе ведения таких работ или оказания услуг обуславливается применением элементов искусственного интеллекта, сложного, наукоемкого оборудования в уникальных производственных процессах, а также специально подготовленным для данных целей персоналом. В частности, критериями отнесения оцениваемой технологии к передовым (advanced-tech) в ОАО «РЖД» считают:

1. Потенциал для дальнейшего развития в течение длительного периода времени (не менее 15 лет) при расширении возможностей сохранения и укрепления позиций холдинга на рынке;

2. Сочетание с пионерными направлениями научно-технического и технологического прогресса на железнодорожном транспорте и по смежным с ним отраслям;

3. Удовлетворение рыночного спроса потребителей за счет повышения качества и номенклатуры услуг и через предоставление дополнительных сервисов;

4. Положительное и устойчивое влияние на эффективность основных технологических процессов в холдинге, рост доходности, развитие клиентской базы, снижение издержек, увеличение производительности труда, энергоэффективности, экологичности и других факторов.

Таким образом, если рассматривать инновацию как определяющий фактор конкуренции, то она представляет собой товар (продукт или услугу), обладающий прежде всего научнотехнологической новизной, имеющий полезные для реальных и потенциальных потребителей 


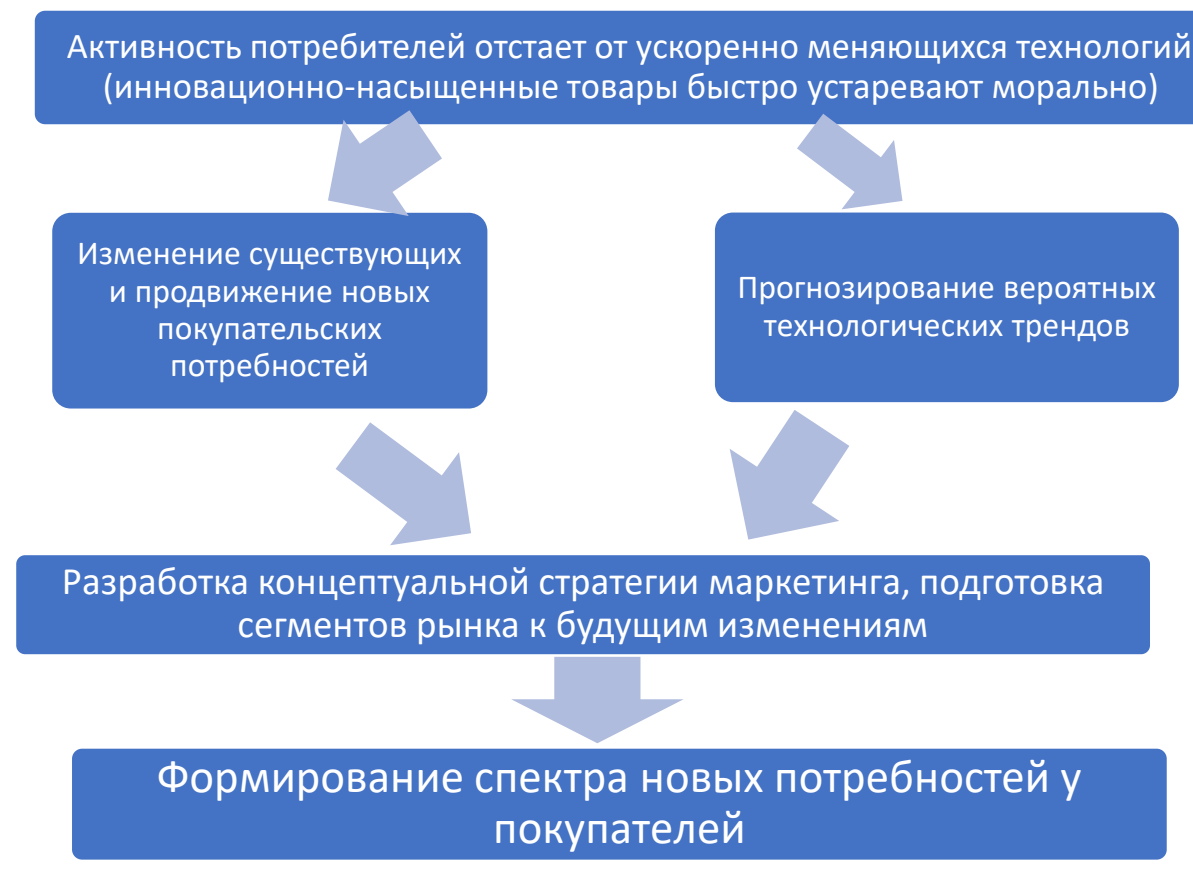

Технологическое прогнозирование при подготовке маркетинговых стратегий

Источник: Составлено авторами на основе: Коротаев А. В., Гринин Л.Е. Кондратьевские волны в мир-системной перспективе / Кондратьевские волны. Аспекты и перспективы / Отв. ред. А. А. Акаев, Р. С. Гринберг. - М.: Либроком, 2012; Кузык Б. Прогнозирование, стратегическое планирование и национальное программирование: Учебник / Б. Кузык, В. Кушлин, Ю. Яковец.-М.: Экономика, 2011.- 604 с.; Юлдашев Р. Т., Воинов А. И. Перспективы развития прорывных технологий VI технологического уклада // Финансовый бизнес, 2016. - № 1.

свойства и области применения [20], а также несущий в себе перспективы коммерциализации, т.е. успешных и эффективных продаж [21] (Рис. $1)$.

\section{Заключение}

Отлаженность механизмов НИС обеспечивается эффективностью управления инновационным процессом, где повышенная активность исследователей и предпринимателей наблюдается в высокотехнологичном секторе. На стыке V и VI укладов к нему относят производство электронных компонентов и приборов, авиационнокосмической техники, компьютерного, офисного и телекоммуникационного оборудования, продукции малотоннажной химии, лекарственных субстанций, а также создание принципиально новых отраслей знаний и производственных индустрий, в частности, генной инженерии, биои нанотехнологий, искусственного интеллекта. По оценкам экспертов, реализуемая на глобальных рынках наукоемкая продукция в целом основана на применении 50-55 макротехнологий, среди которых сегодня нанотехнологии занимают особое место. Нанотехнологизация мирового промышленного производства в среднесрочном периоде может обеспечить объем выручки от реализации нанопродукции на сумму до \$6-6,5 трлн. В этой динамике всё заметнее методы и тренды, исходящие из международных прогностических центров.

Современный рынок не в состоянии ждать, когда наделенные дополнительными потребительскими свойствами товары заполнят свою нишу. Скорость их появления увеличилась в разы (с 3-х лет в начале 2000-х гг. до нескольких недель к 2020-м гг.), что требует от производителей гораздо большего числа вариативных решений на стадиях «посевов» и «стартапов». Здесь всегда актуальны гибкость восприятия инноваций и наличие творческой инициативы в коллективе (школа, колледж, ВУЗ, работа, общественная деятельность). В новом «прозрачном мире» вопросы маркетинга и доступности продукта к конечному потребителю - прерогатива будущего информационно-телекоммуникационных технологий, нейронных сетей и корпоративных экосистем. 


\section{Библиографический список}

1. Воинов А.И. Роль технологического прогнозирования в смене технологических укладов экономики // Экономические науки, 2016. - № 2.- С. 36.

2. Коротаев А.В., Гринин Л.Е. Кондратьевские волны в мир-системной перспективе / Кондратьевские волны. Аспекты и перспективы / Отв. ред. А.А.Акаев, Р. С. Гринберг.- М.: Либроком, 2012.

3. Рыбин М.В. Инновационный менеджмент в горной промышленности: Учебное пособие.- М.: МГИ, 1995.

4. Spohrer J. NBICs (nano-bio-info-cogno-socio) convergence to improve human performance: opportunities and challenges. - USA: Edvard Press, 2002.

5. Кретов С.И. Гуманистическая общественно-экономическая формация. Политическая экономия будущего.-М.: Добротворение, 2015.- Том I, Первая часть.-224 с.

6. Юлдашев Р.T., Воинов А.И. Перспективы развития прорывных технологий VI технологического уклада // Финансовый бизнес, 2016. - № 1.- С. 3-7.

7. Нанотехнологии как ключевой фактор нового технологического уклада в экономике / Под ред. С. Ю. Глазьева и В.В. Харитонова.- М.: Тровант, 2009. - 304 с.

8. Воинов А. И. Эволюция понятия «нанотехнологии» // Изобретательство, 2014. - № 11.- С. 35-39.

9. Отраслевые инструменты инновационной политики / Отв. ред. акад. Н.И.Иванова.- М.: ИМЭМО РАН, 2016. - $161 \mathrm{c}$.

10. Воинов А.И. Проблемы и перспективы венчурного инвестирования в России // Страховое дело, 2018.№ 7.- С. 9-16.

11. Международные экономические отношения: реалии, вызовы и перспективы: монография / [Л. С. Ревенко, В.В.Перская, А. В. Холопов и др.]; под общ. ред. и с предисл. Л. С. Ревенко; Моск. гос. ин-т междунар. отношений (ун-т) МИД России, каф. междунар. экон. отношений и внешнеэкон. связей им. Н.Н.Ливенцева.М.: МГИМО-Университет, 2019.- С. 451, [1].

12. Сардарян А.Р., Чернова В.А. Мультинациональные команды // Управление персоналом, 2008.- № 24.- С. 65-68.

13. Смирнова В.P., Воинов А.И. Венчурные акселераторы в мировой и национальных инновационных экономиках // Экономические науки, 2018. - № 6.- С. 25-31.

14. Торкановский Е.П. Коллективные инвестиции в инновационной экономике: значение и перспективы // Экономика и экономические науки, 2017. - № 1 (65).

15. Гельвановский М. И. Повышение конкурентоспособности российской экономики в условиях глобализации: концептуальные и правовые проблемы // Современная конкуренция, 2007. - № 1 (1).- С. 50-57.

16. Торкановский Е.П. Инвестиционные фонды в инновационной экономике: эволюция и эффективность // ЭКО, 2014. - № 2 (476).- С. 26-33.

17. Зельднер А. Г. Национальная модель социально-рыночного развития России на базе смешанной экономики и механизма государственно-частного партнерства (основные подходы и условия реализации).- М.: Анкил, 2017. - 84 с.

18. Устинова Л. Н. Информационные системы, способствующие формированию интеллектуального капитала и продвижению результатов интеллектуальной деятельности // Копирайт, 2018. - № 1. - С. 13-23.

19. Мухопад В.И. О ресурсах интеллектуальной собственности в оборонно-промышленном комплексе России // Патенты и лицензии, 2017.- № 9.- С. 42-47.

20. Кристенсен К., Рейнор М. Решение проблемы инноваций в бизнесе. Как создать растущий бизнес и успешно поддерживать его рост / Пер. с англ.- М.: АЛЬПИНА ПАБЛИШЕР, 2014.- С. 45.

21. Каганов В.Ш., Рыбин М.В. Как создать и сделать успешным бизнес-инкубатор. Учебно-практическое пособие.-М.: Агроконсалт, 1996.- 112 с. 